\title{
QUALITY IMPROVEMENT RESEARCH
}

\section{Designing a quality improvement intervention: a systematic approach}

\author{
M A van Bokhoven, G Kok, T van der Weijden
}

Qual Saf Health Care 2003;12:215-220

Most quality improvement or change management interventions are currently designed intuitively and their results are often disappointing. While improving the effectiveness of interventions requires systematic development, no specific methodology for composing intervention strategies and programmes is available. This paper describes the methodology of systematically designing quality of care improvement interventions, including problem analysis, intervention design and pretests. Several theories on quality improvement and change management are integrated and valuable materials from health promotion are added. One method of health promotion - intervention mapping - is introduced and applied. It describes the translation of knowledge about barriers to and facilitators of change into a concrete intervention programme. Systematic development of interventions, although time consuming, appears to be worthwhile. Decisions that have to be made during the design process of a quality improvement intervention are visualised, allowing them to serve as a starting point for a systematic evaluation of the intervention.

See end of article for authors' affiliations

Correspondence to: Dr M A van Bokhoven, Centre for Quality of Care Research (WOK) Department of Primary Care, Maastricht University, PO Box 616 , NL-6200 MD Maastricht, The Netherlands; Loes.vanbokhoven@ hag.unimaas.nl
M any different interventions have been developed to enhance the implementation of research findings or innovations in daily practice and to change professional or team performance. The Cochrane Effective Practice and Organization of Care (EPOC) group have summarized their effects in several reviews and conclude that the effectiveness of most interventions is heterogeneous and limited, although combined and multifaceted efforts are generally more promising. ${ }^{2}$ Explanations for these disappointing results include the difficulty of changing existing practice, non-optimal choices of intervention strategies, and the use of inadequate methods to design and evaluate interventions. ${ }^{3-5}$ The use of rigorous research methods in quality improvement has now been generally accepted for evaluation of interventions, and increasingly also for the problem analysis of the healthcare topic that is to be changed. However, a scientific approach should also be accepted for the design process of the intervention. In the current situation, many developers of interventions tend to select their strategies intuitively, usually based on their familiarity with a specific strategy. The choice of the format of an intervention often pre- cedes the choice of its contents. However, it is generally accepted that, to be effective, interventions should be targeted at specific barriers to and facilitators of change. ${ }^{467}$ Systematic development of interventions and tailoring their content and format to the specific features of a target group and setting seems necessary to improve the effectiveness of patient care.

Steps to improve quality of care have been described as a cyclical process (fig 1). ${ }^{689}$ While the problem analysis step has been specified in the literature by several authors, ${ }^{6}{ }^{1011}$ the literature on quality improvement research so far provides little information on the systematic translation of knowledge about barriers to and facilitators of change into concrete quality improvement interventions. This paper focuses on the methodology of designing and pretesting such interventions. It addresses the question of how to link an intervention to the target problem in a transparent way. Several theories are described, both from the field of quality improvement and change management and from that of health promotion. As an example we use a quality improvement project on the problem of unnecessary laboratory test ordering by GPs in cases of medical uncertainty for which we have developed an intervention.

\section{PROBLEM ANALYSIS}

Ideally, problem analysis precedes the design of an intervention. This analysis begins by describing the healthcare problem to be addressed in quantifiable measures, followed by the barriers to and facilitators of change, and then the target population.

\section{Describing the problem}

Careful targeting of the intervention requires that the situation that is to be improved by the intervention is very clear. Several methods are available for the collection of data on processes, outcomes, and costs. It is advisable to take small but representative samples of professionals, patients, or written data, to use both quantitative and qualitative designs, and to fit the measurements into daily routines as much as possible. ${ }^{12}$ The ultimate goal of every intervention is to improve the health and quality of life of patients or to maintain high standards of quality at lower costs. The intended improvement of health, quality of life, and quality of care should therefore be described in quantifiable terms, and standards of good quality of care should have been set. ${ }^{13}{ }^{14}$ 


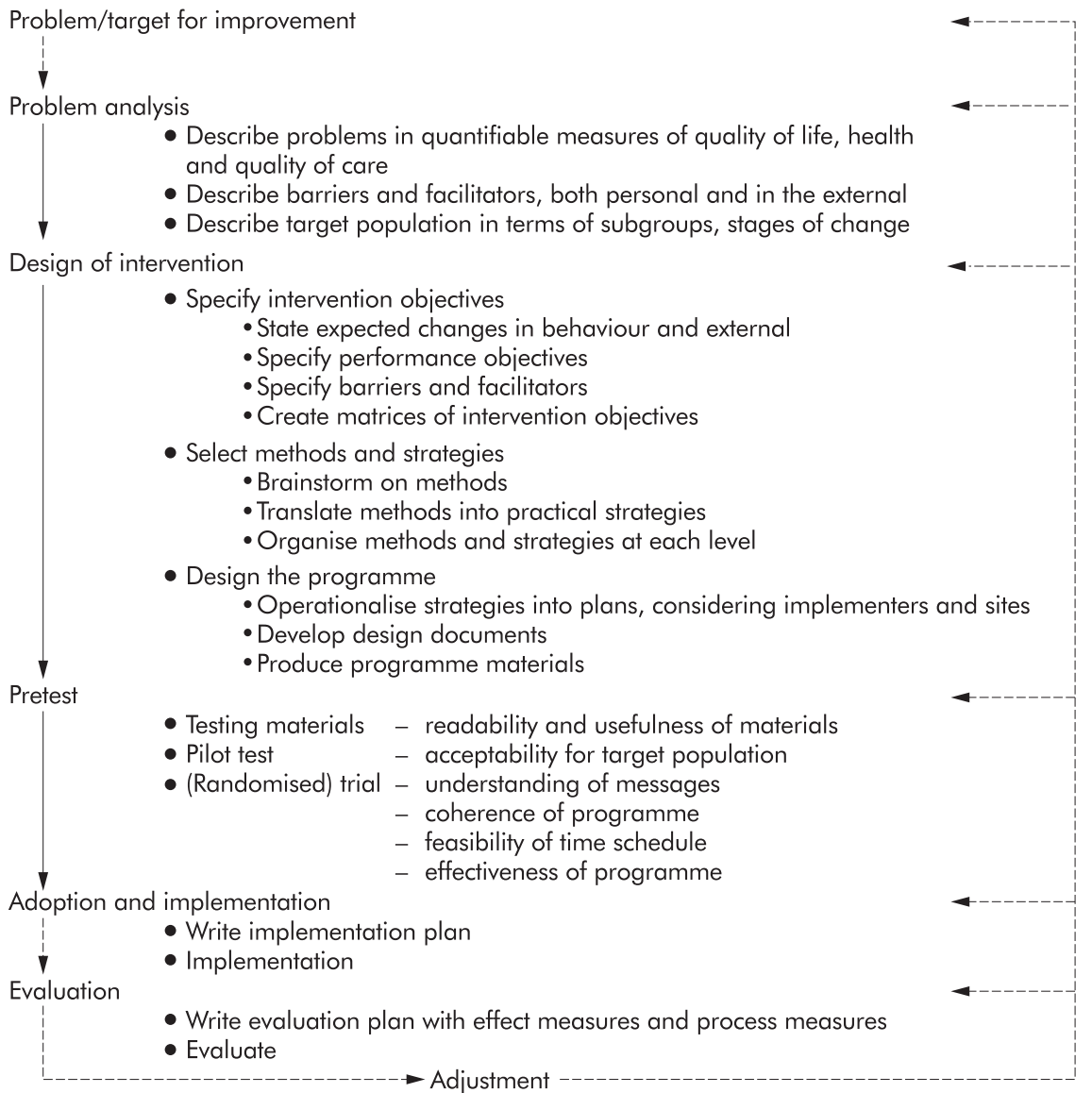

Figure 1 Design process for quality of care improvement interventions.

\section{Identifying barriers to and facilitators of change}

In tailoring the intervention, the next step is to identify barriers to and facilitators of change. Figure 2 presents a modified combined model based on the PRECEDE-PROCEED concept and the theory of planned behaviour, ${ }^{15}{ }^{16}$ showing different types of potential barriers and facilitators and the way in which they can influence professional behaviour and quality of life. Barriers and facilitators may be located within the person of the professional or in his or her external context. ${ }^{7}$ Factors inherent in the professional-such as attitudes, perceived social influence, and self-efficacy-stimulate the intention to change, while skills are needed for actual change. Context factors can have different levels. External influence can come from other individuals (interpersonal level)—for example, a patient requesting treatment-but also from a larger group such as a nursing team (organisational level), a local professional society (community level), or a whole nation (societal level)-for example, through legislation or insurances. Major factors at the organisational level include the organisation's mission, goals, policies, procedures, structures, technologies, physical setting, collaboration, and resources. ${ }^{17}{ }^{18}$ At the community level, barriers and facilitators include collective self-efficacy, political efficacy, and motivation to act. ${ }^{19}$ At the societal level changes take place through political influence. Factors influencing the political decision process include the place where policies are made-whether outside or within the government, or within the government but requiring support from outside for passage ${ }^{20}$-and groups influencing the policy makers such as professional societies or patient groups. ${ }^{21}$ The barriers and facilitators at different levels can be identified by detailed qualitative analysis of a few situations followed by quantitative studies among professionals, patients, and institutions to find out the relative importance of the various factors. Such studies can use questionnaires, interviews, and observations. ${ }^{22}$

\section{Describing the target population}

A third component of problem analysis is the description of the target population in terms of aspects influencing the change process such as the information channels they use.

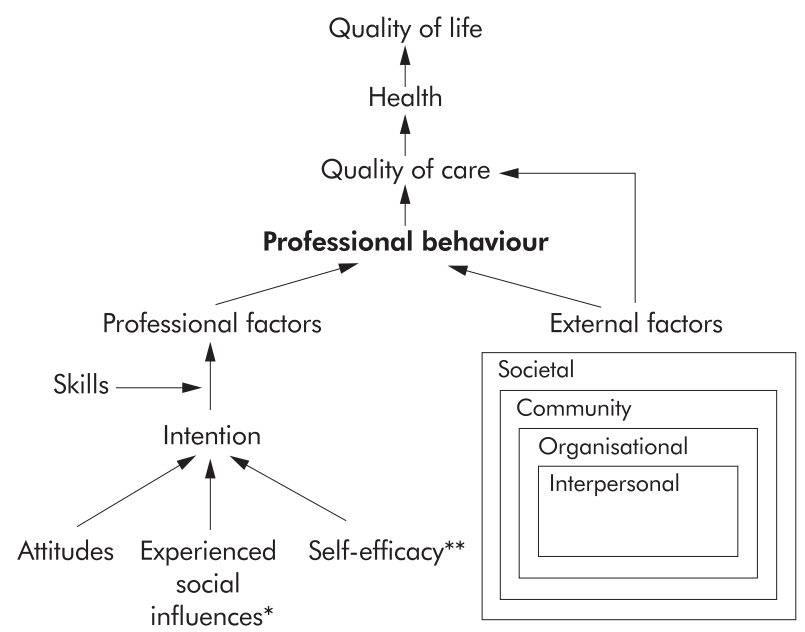

*Subjectively perceived social influences (as opposed to interpersonal external factors, which are objective social influences). ** Trust in own capacities to perform according to standards of good care.

Figure 2 Model of barriers and facilitators. 
One aspect of the target population that needs to be clarified is the "stage of behavioural change". Behavioural changes in individuals (both at the personal and the interpersonal level) usually take place in a particular order. ${ }^{10}{ }^{112324}$ Prochaska $^{11}$ identified five stages:

(1) Pre-contemplation: the target population is not aware that their behaviours should and can be improved.

(2) Contemplation: the target population reflects on the advantages and disadvantages of changing their behaviours.

(3) Preparation: concrete plans for change are made.

(4) Action: changing behaviour starts.

(5) Maintenance: the target population decides whether to continue the new behaviour or to relapse to the former behaviour.

Each stage sets specific goals for interventions: drawing attention to the message in stage 1 , understanding the message in stage 2 , changing barriers and facilitators in stage 3 , changing behaviour in stage 4 , and maintaining behaviour in stage 5. Subgroups within the target population may have different characteristics and therefore require different interventions.

Change at the organisational level also seems to take place in a particular order. Goodman et a ${ }^{17}$ have identified seven stages:

(1) Noticing the problem.

(2) Searching for possible responses.

(3) Evaluating alternatives.

(4) Deciding to adopt a course of action based on a selected number of responses.

(5) Initiating action within the system, which requires policy changes and resources necessary for implementation.

(6) Implementation, including some organisation members changing their work behaviours and relationships.

(7) Institutionalising the change, which means including it in strategic plans, job descriptions, and budgets so that it becomes a routine part of organisational operations.

Such distinctions between stages of change may be very important as the key actors at which the intervention is targeted can vary depending of the stage of change. ${ }^{25}$ Thus, in the earlier stages senior level staff are the target population where decisions are made to start the change process, and also at the final stage where the decision is made whether to institutionalise the change or not. Mid-level staff are important during the adoption and early implementation stages, in which skills to introduce procedures and provide training on the innovation are critical. In the adoption stage, the people who have to apply the change in their daily professional practice form the target population of the intervention.

An example of problem analysis is given in box 1 .

\section{THE ACTUAL DESIGN PROCESS}

Based on the findings of the problem analysis, the actual design process can start. The steps described below have been derived from the "intervention mapping" theory, a method for designing interventions originally aimed at unhealthy behaviours ${ }^{26} 27$ that appeared to be helpful.

\section{Specification of performance and intervention objectives}

This step focuses on linking barriers and facilitators found in the problem analysis to concrete behaviours of professionals and on deriving objectives for quality improvement from this relation. It is always people who play a crucial role in managing change, even at the external level. This step therefore begins with reframing both problem behaviours and external causes found in the problem analysis into desirable behaviours

\section{Box 1 Example of problem analysis ${ }^{31-34}$}

General practitioners frequently see patients with unexplained complaints. The complaints are usually self-limiting and the value of blood testing is nil due to the low pretest probability of disease. For this reason, a national guideline recommends postponing blood testing in this category of patients by 1 month. Nevertheless, many GPs request several blood tests immediately, which might have negative effects such as unnecessary further investigations, fear in patients, somatization, and high costs. The goal of the intervention is to stimulate GPs to adhere to the national guideline.

A qualitative study was performed to collect information on the barriers and facilitators influencing the test requesting behaviour. Consultations by the GPs were observed and field notes were taken on a pre-structured form. Afterwards, GPs were interviewed about barriers to and facilitators of test ordering behaviour for "unexplained complaints" in a non-pre-structured way. This was followed by a search of the literature on possible barriers and facilitators. A questionnaire survey of GPs was then carried out which more specifically dealt with different types of barriers and facilitators, with questions on experiences with changing behaviour, opinions about the value of blood testing, perceived social influence from patients and colleagues or others on test ordering, grading their own capacities to change test ordering behaviour, and interest in postgraduate education. GPs were also asked to rate their stage of change regarding consultation skills and test requesting behaviour.

Since many GPs reported experiencing pressure from patients to do laboratory tests, a short questionnaire survey was held among patients in the waiting room before they consulted their GPs. Patients were asked questions about what they thought their GPs could do for them. No further research was done at the other external levels because successful interventions on test requesting behaviour at those levels had already been implemented before, so there was not much room for improvement. In addition, as many GPs work in single person practices, the external level (organisational and societal) in Dutch general practice has less impact than, for example, in hospitals.

Some examples of the barriers and facilitators found are presented below:

- Attitudes

- Blood testing does not have harmful effects

- Blood testing is a more efficient strategy than explaining a wait and see policy

- Perceived social influences

- Patients expect blood testing

- Patients are anxious

- Self-efficacy

- Perceived capability to resist pressure from patients

- Difficulty of postponing testing when under pressure of time

- Skills

- Routines (non-conscious skills)

- Communication skills

- Diagnostic skills (doing laboratory tests instead of physical examination)

- External factors

- Exaggerated expectations of tests among patients

- Lack of knowledge about limitations of tests among patients 
Table 1 Example of part of a matrix with intervention objectives for GPs

\begin{tabular}{|c|c|c|c|}
\hline \multirow[b]{2}{*}{ Performance objectives } & \multicolumn{3}{|l|}{ Barriers and facilitators } \\
\hline & $\begin{array}{l}\text { High outcome expectation of } \\
\text { tests }\end{array}$ & Lack of communication skills & Uncertainty of GP \\
\hline $\begin{array}{l}\text { Performs adequate history } \\
\text { taking and physical } \\
\text { examination }\end{array}$ & $\begin{array}{l}\text { GP states that physical } \\
\text { examination is a way of taking } \\
\text { patients' complaints seriously }\end{array}$ & $\begin{array}{l}\text { GP asks patients about reasons for } \\
\text { encounter and chooses formulation which } \\
\text { he/she feels most comfortable with }\end{array}$ & $\begin{array}{l}\text { GP states that testing does not yield more } \\
\text { information than performing physical } \\
\text { examination }\end{array}$ \\
\hline $\begin{array}{l}\text { Explains findings and } \\
\text { conclusions to patient } \\
\text { appropriately }\end{array}$ & $\begin{array}{l}\text { GP states the importance of } \\
\text { explaining findings and } \\
\text { conclusions to patient }\end{array}$ & $\begin{array}{l}\text { GP demonstrates the use of different } \\
\text { formulations to explain findings from history } \\
\text { taking and physical examination to patients }\end{array}$ & $\begin{array}{l}\text { GP shows patients he/she is convinced that } \\
\text { findings from history taking and examination } \\
\text { are sufficient to feel reassured }\end{array}$ \\
\hline $\begin{array}{l}\text { Discusses a } 1 \text { month "wait } \\
\text { and see" policy }\end{array}$ & - & $\begin{array}{l}\text { GP uses instruction materials in addition to } \\
\text { verbal message }\end{array}$ & $\begin{array}{l}\text { GP shows awareness that his/her own } \\
\text { uncertainty is a reason to request blood tests }\end{array}$ \\
\hline
\end{tabular}

in practice-performance objectives such as "GP discusses a 1 month "wait and see" policy in consultations with patients presenting unexplained complaints" or "national college of GPs disseminates guideline to all GPs". These performance objectives need to be specific and measurable in order to tailor the intervention to the heart of the problem and to be able to evaluate the effects of the intervention later. In addition, the frequency of the behaviours and the situations in which they should be performed are specifically described (table 1, column 1). Goals may include not only changing behaviour but also maintaining behaviour. ${ }^{28}$ As a check it might be important to ask members of the target population and service providers by interviews or questionnaires, for example, whether they consider the objectives important for achieving the improvement.

Achieving the performance objectives requires the barriers and facilitators to be influenced. Many barriers and facilitators are usually found and, since it is impossible to target an intervention to all of these, a selection has to be made. Two criteria for selecting barriers and facilitators are "importance" and "changeability". If a barrier or facilitator is not important, efforts to change it do not make sense-for example, a "wait and see" policy of 1 month is cheaper than immediate blood testing in patients with unexplained complaints as most complaints are self-limiting within 1 month. However, GPs consider costs to be only a minor factor in determining their behaviour so it is not useful to design an intervention providing information about costs to GPs. The same applies to changeability-for example, GPs consider a lack of time per consultation as an important reason for requesting blood tests instead of explaining to patients the limited use of testing which is more time consuming. The time scheduled per consultation, however, can hardly be changed as it is based on national rules. Sometimes information about importance and changeability can be extracted from the literature or from the quantitative research executed in the problem analysis phase.

Performance objectives (table 1 , column 1) and selected barriers and facilitators (table 1, row 1) can next be linked in a matrix, allowing a concrete intervention objective to be formulated in each cell of the matrix (table 1, cells). For example, in order to achieve the goal of having GPs use adequate history taking and physical examination in practice (performance objective), the intervention should address barriers such as "uncertainty of GP" so that, as a result of the intervention, the GP "states that laboratory testing does not yield more information than physical examination" (intervention objective). In the example shown in table 1 only some of the barriers have been worked out. In addition, the problem analysis revealed that patients have high pre-consultation expectations of laboratory tests and demand tests, which influences the behaviour of GPs. The intervention was therefore also targeted at the patients. As patients require a different intervention from GPs, their goals and their barriers and facilitators were entered into a different matrix which is not shown here. As stated above, we decided not to target the intervention at other external levels.

Like performance objectives, intervention objectives are formulated in terms of measurable behaviours, but intervention objectives are the aims of the intervention programme rather than the aims of performance in daily practice. If the problem analysis reveals that there are target populations at more than one level or that different subgroups in the target population require different interventions, separate matrices should be drawn up for every group. Interventions may thus be targeted at different people or organisations including assistants, patients, practice teams, hospital departments, politicians, and insurance companies

\section{Selection of methods and strategies}

Once concrete intervention objectives have been defined, one can start searching for concrete methods and strategies for achieving these objectives. A good start is to have a brainstorming session in an expert group and to make a provisional list of potential methods and strategies. Who is "expert" depends on the problem for which an intervention is being developed and may include members of the target population. The list can be extended by a literature search using resources such as the EPOC database..$^{29}$ To enable a broad search, three approaches to searching literature databases are recommended:

(1)By medical or health care subject-for example, "laboratory testing" or "unexplained complaints". The Cochrane Library includes several useful systematic reviews of interventions aimed at various topics. ${ }^{29}$ Descriptive studies delineating variants of a service can also be of value. ${ }^{3}$

(2)By concepts from the provisional list of methods and strategies or the barriers, facilitators, and behavioural objectives from the previous step-for example, "explanation of findings to patients" or "uncertainty".

(3)By known theories-for example, "goal setting theory" or "community organisation theory", or taxonomy of known strategies as used by the EPOC group. It is advisable to use this search strategy after the other strategies have been used to enable a broad focus on a number of methods.

If it is not only the personal or interpersonal levels that are important, databases from business or political sciences can be used to extend the search. Overviews of methods can be found in several books and papers on health promotion, quality improvement, and implementation of guidelines. ${ }^{27}{ }^{30}$ Objectives, methods, and strategies found can then be listed and the conditions under which they are effective can be added. Once sufficient methods have been collected, a selection can be made (box 2). 
Box 2 Example of theories and strategies illustrating the search for theories on test ordering skills and the related barriers and facilitators

(1) Brainstorming session

- Strategies about skills training such as stepwise explanation of complex skills, giving opportunities to practise both in a laboratory situation and in practice.

\section{(2) Literature search}

- Search on "unexplained complaints" and related topics such as "irritable bowel syndrome", yielding papers on methods of cognitive behavioural therapy.

- Search on concepts such as "communication skills", adding methods such as "providing knowledge about skills", "attention to both skills and self-efficacy", and "offering coping strategies for difficult situations".

- Search on general theories applicable to skills changes: "rewarding systems", "goal setting theory", and "giving feedback".

\section{(3) Pragmatic selection of methods and strategies}

- Limiting conditions included the fact that group activities should take place in a safe environment where one is allowed to make mistakes.

\section{Programme design}

The result of the previous step is a list of methods and strategies which can be integrated into a coherent intervention. This requires a creative process. Brainstorming about possible intervention components and materials may be a good start. Interesting materials may have come up during the search of the literature for methods and strategies. However, in translating the methods and strategies into intervention components, several conditions should be kept in mind-for example, different "segments" of the target population may require different strategies, the stages of behavioural change in the target population, and communication variables are important for the order and format of the components of the intervention. ${ }^{24}$ Different stages of the change process may require different messages and different modes of transmission. According to McGuire, ${ }^{24}$ interventions should have a striking "appearance" to attract attention, while actually getting people to change depends more on the cogency of the message.

Another important condition is the opportunity to implement the intervention in daily practice as mentioned by Grol et al. ${ }^{7}$ Limiting factors in this respect include budget, human resources, available time, existing intervention formats, and characteristics of the organization that actually implements the intervention.

\section{Pretest}

Before the intervention can be implemented it is recommended to do a pretest. Pretests can consist of several stages, each of which can reveal information that requires adjustment of the intervention programme. The first stage involves testing the separate materials such as leaflets or course books. Such testing can be done by means of "technical" methods like readability formulae and tests of understanding, or by asking experts and members of the target population to try out the materials and to give their opinions, preferably using qualitative methods. A combination of approaches is advisable. The second stage involves running the intervention programme in a pilot group to test its coherence and the time schedule and to get an impression of its acceptability in the target population. Again, the evaluation of this stage should be done mainly by qualitative methods. The final stage before large scale implementation involves testing the intervention for its effectiveness on a smaller scale. The best method to evaluate its effectiveness is usually a randomised clinical trial. Variables
Box 3 Possible intervention programme targeted at different levels

The intervention goals are shown in brackets. The intervention was limited to the level of GPs and patients.

GPs

- Educational group meetings providing information, learning from peers, skills training and feedback (repetition of messages, improvement of information uptake, knowledge enhancement, problem awareness, attitude change, selfefficacy enhancement, skills improvement)

- Practice visit by expert (repetition of messages, tailoring of messages to individual's stage of change)

- Goal setting for try-out in GP's own practice (to stimulate actual practising)

- Introduction of materials to offer to patients (to reduce "empty hands feeling" among GPs, self-efficacy enhancement)

Patients

- Video message in waiting room (awareness of problem, knowledge enhancement)

- Leaflet (knowledge enhancement, attitude change)

- Diaries about complaints and diet (enhancing patients sense of control and self-responsibilityl

\section{Laboratories}

- Feedback on test requesting behaviour (knowledge enhancement)

- Small group quality improvement in local GP groups by using feedback data (social influence)

Regional cooperation of professional societies

- Problem-based laboratory test requesting forms (change of routines)

National College of General Practitioners

- Evidence-based national guidelines (knowledge enhancement, improvement of credibility of message)

- Provision of postgraduate education (knowledge enhancement)

can be extracted from the problem analysis while process measures such as those concerning participation rates should also be collected at this stage.

A possible intervention programme targeted at different levels is shown in box 3.

\section{DISCUSSION}

It is generally accepted that systematic development of quality improvement interventions is needed if such interventions are to be effective. Interventions should have the correct objectives, be targeted at the barriers and facilitators related to achieving the desired performance, and have programme components and materials adapted to specific objectives, target populations, barriers, and facilitators. In addition, it may be necessary to target the intervention not only at individual professionals but also at external factors which influence professional behaviour and the quality of care. The approach is ideally theory driven.

Several authors have described phases of the intervention design process; Green and Kreuter have described a problem analysis (PRECEDE) and evaluation (PROCEED) of interventions, ${ }^{15}$ and McGuire has described the requirements of educational messages and materials given the stage of the change process. ${ }^{24}$ However, no integrated approach to the design process from the perspective of the intervention designer-linking problem analysis, programme design and pretest and specifying the programme design phase-has yet been provided. Bartholomew et $a^{2627}$ have done interesting 


\section{Key messages}

- A scientific approach is needed to the design of quality improvement interventions.

- Systematic development of interventions, including tailoring their content and format to the specific features of target groups and setting, is necessary to improve the quality of patient care.

- Decisions made during the design process are an appropriate starting point for systematic evaluations of quality improvement interventions.

- Further empirical research is needed to develop more evidence based criteria for the selection of barriers, facilitators, theories and strategies and to test promising theories in practice.

work on this topic in the field of health promotion, developing intervention mapping - a systematic method of linking problem analysis, programme design and evaluation and integrating theories and scientific evidence in the design process. It also visualises the "crossroads" at which choices about the route to be followed have to be made. This method may also be applicable in designing quality of healthcare improvement interventions. Designing such interventions is an iterative process in which the designers go back and forth through the steps of problem analysis, design and pretesting. Throughout the process, information becomes available which influences previous steps or a lack of knowledge is revealed which requires additional study.

Going through the steps of such an intervention design can be difficult and time consuming. It requires study, creativity, expertise from social sciences, and close cooperation between project group members, target population, materials designers, and implementers. A pragmatic balance should be sought between collecting information and constructing the intervention. However, since interventions are often not very effective, the investment in carefully preparing, designing, and testing such an intervention may be worthwhile.

It is important to involve future users of the intervention in the design process from the start. Writing an evaluation plan is easy after proceeding through the previous steps. As all goals have been formulated in measurable entities, measures for evaluation follow directly from the problem analysis and matrices. Besides, choices of barriers and facilitators, theories and formats have been explained so that the effects of the intervention can be linked to these in the process evaluation. The choices made might explain unexpected effects and, in the meantime, offer ideas for adjusting the intervention.

The selection criteria used during the intervention design process for barriers and facilitators, methods, strategies, formats and materials, for example, are still mainly pragmatic and several methods are mainly theory based so further empirical research is needed to develop more evidence based selection criteria and to test promising theories in practice. However, the systematic approach makes the intervention transparent.

We conclude that there are possibilities for designing quality improvement interventions systematically. Intervention mapping appears to be a useful method, not only for health education interventions but also for quality improvement interventions.

\section{Authors' affiliations}

M A van Bokhoven, T van der Weijden, Centre for Quality of Care Research/Department of General Practice, Maastricht University, The Netherlands

G Kok, Department of Experimental Psychology, Maastricht University

\section{REFERENCES}

1 Bero LA, Grilli R, Grimshaw JM, et al. Getting research findings into practice: closing the gap between research and practice: an overview of systematic reviews of interventions to promote the implementation of research findings. BM 1998;317:465-8

2 Grimshaw JM, Shirran L, Thomas R, et al. Changing provider behaviour: an overview of systematic reviews of interventions. Med Care 2001;39:॥2-45.

3 Campbell $M$, Fitzpatrick R, Haines $A$, et al. Framework for design and evaluation of complex interventions to improve health. $B M$ 2000;321:694-6.

4 Davis DA, Thomson MA, Oxman AD, et al. Changing physician performance. A systematic review of the effect of continuing medical education strategies. JAMA 1995;274:700-5.

5 Wensing $\mathbf{M}$, van der Weijden T, Grol R. Implementing guidelines and innovations in general practice: which interventions are effective? $\mathrm{Br} J$ Gen Pract 1998;48:991-7.

6 Grol R. Beliefs and evidence in changing clinical practice. BM 1997;315:418-21.

7 Grol RPTM. Implementing guidelines in general practice care. Qual Health Care 1992:1:184-91.

8 Ovretveit $\mathbf{J}$. A team quality improvement sequence for complex health problem. Qual Health Care 1999;8:239-46.

9 Langley G, Nolan K, Nolan T. The improvement guide. San Francisco: Jossey Bass, 1996.

10 Rogers EM. Diffusion of innovations. 4th ed. New York: Free Press, 1995.

11 Prochaska JO, Di Clemente CC. The transtheoretical approach: crossing traditional boundaries of therapy. Homewood, IL: Dow Jones-Irwin, 1984.

12 Nelson EC, Splaine MaE, Batalden PB, et al. Building measurement and data collection into medical practice. Ann Intern Med 1998;128:460-6.

13 Woolf SH. Practice guidelines, a new reality in medicine. II. Methods of developing guidelines. Arch Intern Med 1992;152:946-52

14 Grimshaw JM, Eccles M, Russel I. Developing clinically valid practice guidelines. J Eval Clin Pract 1995;1:37-48.

15 Green LW, Kreuter MW. Health promotion planning. An educational and environmental approach. 2nd ed. Mountain View: Mayfield Publishing Company, 1999.

16 Kok GJ, De Vries H, Mudde AN, et al. Planned health education and the role of self-efficacy: Dutch research. Health Educ Res 1991;6:231-8.

17 Goodman RM, Steckler A, Kegler MC. Mobilizing organizations for health enhancement: theories of organizational change. In: Glanz K, Lewis FM, Rimer BK, eds. Health behaviour and health education: theory, research and practice. 2 nd ed. San Fransisco: Jossey-Bass, 1997: 287-312.

18 Fawcett SB, Paine-Andrews A, Francisco VT, et al. Using empowerment theory in collaborative partnerships for community health and development. Am J Community Psychol 1995:23:677-97.

19 Minkler M, Wallerstein N. Improving health through community organization and community building. In: Glanz K, Lewis FM, Rimer BK, eds. Health behavior and health education: theory, research and practice. San Fransisco: Jossey-Bass, 1997: 241-69.

20 Cobb RW, Elder CD. Participation in American politics: the dynamics of agenda building. Baltimore: Johns Hopkins University Press, 1983.

21 Laumann EO, Knoke D. The organizational state: social choice in national policy domains. Madison: University of Wisconsin Press, 1987

22 Pope C, Van Royen P, Baker R. Qualitative methods in research on healthcare quality. Qual Saf Health Care 2002;11:148-52.

23 Fishbein M, Ajzen I. Belief, attitude, intention and behavior: an introduction to theory and research. Reading, Mass: Addison Wesley, 1975.

24 McGuire WJ. Attitudes and attitude change. In: Lindzey G, Aronson E, eds. The handbook of social psychology. New York: Random House, 1985: 233-346.

25 Miles MB, Huberman AM. Qualitative data analysis. An expanded sourcebook. Thousand Oaks: Sage Publications, 1994.

26 Bartholomew LK, Parcel GS, Kok G. Intervention mapping: a process for developing theory- and evidence-based health education programs. Health Educ Behav 1998;25:545-63.

27 Bartholomew LK, Parcel GJ, Kok G, et al. Intervention mapping. Designing theory-and evidence-based health promotion programs. Mountain View, California, London, Toronto: Mayfield, 2001

28 Marlatt GA, Gordon JR. Relapse prevention: maintenance strategies in the treatment of addictive behaviors. New York: Guilford, 1985.

29 Bero L, Grilli R, Grimshaw JM, et al. Cochrane Effective Practice and Organisation of Care Group. The Cochrane Library. Issue 3. Oxford: Update Software, 2002.

30 Glanz K, Lewis FM, Rimer BK. Health behaviour and health education: theory, research and practice. 2nd ed. San Francisco: Jossey-Bass, 1997.

31 Zaat JO, Van Eijk JT, Bonte HA. Laboratory test form design influences test ordering by general practitioners in the Netherlands. Med Care 1992;30: 189-98.

32 Winkens RAG. Improving test ordering in general practice. The effects of individual feedback. Riiksuniversiteit Limburg, 1994.

33 Van der Weijden T, Van Velsen M, Dinant GJ, et al. Unexplained complaints in general practice. Prevalence, patient expectations, and the professional's test ordering behavior. Med Decision Making 2003 (in press).

34 van der Weijden T, van Bokhoven MA, Dinant G-J, et al. Understanding laboratory testing in diagnostic uncertainty: a qualitative study in general practice. Br J Gen Pract 2002;52:974-80. 